\title{
Science plus technology to address challenges in determining the efficacy of neuroprotective/neurorestorative therapies
}

\author{
Rafael Franco ${ }^{1,2 *}$ \\ ${ }^{1}$ School of Chemistry, Universitat de Barcelona, Barcelona, 08028 Barcelona, Spain \\ ${ }^{2}$ Network Center, Neurodegenerative Diseases (CiberNed), Spanish National Health Institute Carlos III. 28031 Madrid, Spain
}

*Correspondence: Rafael Franco, Departament de Bioquímica i Biomedicina Molecular, Facultat de Biologia, Universitat de Barcelona, 08028 Barcelona, Spain.rfranco@ub.edu; rfranco123@gmail.com

Academic Editor: Rafael Franco, Universitat de Barcelona, Spain

Received: January 2, 2021 Accepted: January 4, 2021 Published: August 5, 2021

Cite this article: Franco R. Science plus technology to address challenges in determining the efficacy of neuroprotective/ neurorestorative therapies. Explor Neuroprot Ther. 2021;1:1-6. https://doi.org/10.37349/ent.2021.00001

\section{Introduction}

The main challenge in neuroprotection is to demonstrate in humans the efficacy of any neuroprotective therapy. Exploration of Neuroprotective Therapy (ENT) highlights interest in the classical pharmacology, in sophisticated techniques such as deep brain stimulation and in traditional medicine tools (herbal medication, meditation...), etc.

While Alzheimer's disease (AD) and Parkinson's disease (PD) require neuroprotective interventions to reduce neuronal death whereas amyotrophic lateral sclerosis, spinal cord injuries, autism, etc. may require restoration or both protection and restoration. The challenges are manifold and the 21st century should be able to provide answers to many of the diseases that currently do not have an effective therapy to treat of slow down disease progression.

\section{Nervous system diseases' diversity, risk assessment and the discovery of successful therapeutic strategies}

Diseases affecting the peripheral or central nervous system share some features: alteration of energetic balance, and/or local depletion of a given neurotransmitter, and/or alteration of brain circuits and/or neuronal death and/or glial cell death, etc. Similarly, measuring the effectiveness of a given intervention is a challenge whose solution may vary from one nervous system disease (NSD) to another, but there may be shared parameters to measure, e.g., the level of glucose in the cerebrospinal fluid (CSF).

Omics approaches provide a large amount of data that, in fact, provides valuable information. In terms of NSD, genomics provides risk factors. For late-onset degenerative diseases (e.g., non-inherited AD and PD) it is questionable whether knowing the risk is desirable or not [1-9]. Personally, I would not want to live knowing that I am at high risk for $\mathrm{AD}$ to live in fear and end up with a healthy brain but a fatal heart attack. 


\section{The two phases in NSDs}

In some NSDs in which neuronal death occurs, two phases appear that may require differential therapeutic approaches. Although targeting neurons may be good in prevention and first clinical stages, targeting glial cells is instrumental at advanced stages. Among them microglia, upon activation, may be proinflammatory (M1 phenotype) or neuroprotective (M2 phenotype) [10]. Time may be a factor convert M1 into M2 cells and, also, there is in vitro evidence of interventions that can skew the M1 into the M2 phenotype. Combining these two discoveries it would be interesting to explore time windows of therapeutic intervention.

Positron emission tomography (PET) is advancing to detect neuroinflammation in the human brain through the use of probes that interact with microglial molecules. As far as we know, these procedures are not routine, that is, they are already in the experimental phase [11-20]. The development of M1 and M2 PET ligands would help decide when therapies should temper neuroinflammation and when they should be addressed to boost neuroprotection.

\section{Learning from other diseases}

Along with age-related neurodegenerative diseases, three other common diseases are on the rise in recent decades, namely diabetes (type II), hypertension, and hypercholesteremia. There are interventions for all of them that do not cure the underlying cause, but allow patients to enjoy relatively normal lives. Parameters to evaluate the efficacy of therapies to combat these therapies are well defined.

Centuries back when nobody knew what a carbohydrate was, diabetes was diagnosed by the sweetness of the urine. After discovering that sweetness was due to sugars, and that glucose was the culprit, the last two centuries allowed progress in simple tests to determine glucose in blood urine and CSF [21, 22]. It should be also noted that it is possible to assess whether the patient has the disease under control by measuring A1c glycosylated hemoglobin [23-26].

Can surrogate parameters for NSD be found in blood? This is one of the main questions although the answer is likely not. Desirable but very difficult. Therefore, other body fluids should be considered and the field must be open to develop strategies to measure parameters in the CSF.

\section{Telemetry and nanotechnology to measure CSF components}

In the case of NSDs, the two legs to support the therapeutic corpus are neuroscience and bioengineering. While advances in neuroscience are difficult to predict, engineers can design and build almost any device. The results of Neuroscience in the case of some NSDs have been poor, but the technological advances in Medicine have been notable. ENT welcomes articles from neuroscientists who think of useful devices to address neuroprotection/neurorestoration and that can be built by bioengineers. Telemetry (see below) is one of the techniques that show potential and neuroscience must benefit of telemetry and any other technological advance that is deemed necessary. The diabetes research field is gaining momentum due to tools that allow real-time measurement of glucose levels by telemetry [27-30] thus avoiding changes due to stress in animal handling, circadian rhythms, etc. Who would not want to know whether CSF glucose levels, that in a healthy individual are $60-70 \%$ of those in blood, are altered in neurodegeneration and are restored by a given neuroprotective therapy?

Technology has advanced enormously in the last decades and the Neuroscience field must take advantage of its present and future possibilities. ENT journal will welcome papers showing bioengineers and nanotechnology researchers the way to assess parameters measuring the efficacy of neuroprotective therapies.

\section{Longitudinal studies}

Coffee/tea consumption reduces the risk of suffering from PD or AD; there are solid longitudinal studies show that natural methylxanthines: caffeine in coffee (or cola drinks) and theophylline in tea are neuroprotective (via blockade of adenosine $\mathrm{G}$ protein-coupled receptors) [31-41]. 
Natural compounds or approved drugs considered as nootropics, i.e. those that improve brain function, must be subjected to longitudinal studies to show neuroprotective potential [42-50]. Ideally these studies should be performed in humans but ENT is open to receive submissions of epidemiological-like longitudinal studies in animals. Taking AD models, which require time to manifest cognitive deficits: could these deficits manifest themselves later in animals that consume nootropics?

Finally, another version of longitudinal studies to address neuroprotective potential is to analyze data of aged people that take pills (antihypertensive, antidiabetic, etc.). Do some pills reduce/increase the age at which a certain NSD occurs? Do patients on memantine have accelerated cognitive decline or live longer or shorter than patients taking another anti-AD drug? The data is there, and Governments, Institutions and Hospitals should make possible access to the data (preserving the identity of the individuals). Similarly, do ethnic groups present less impact from NSDs due to their lifestyle? Do societies that started few years ago to take pills have more/less affectation of NSDs?

\section{Conclusions}

ENT is born with the spirit of serving as a platform to accelerate the translation of therapies to patients with diseases of the peripheral or central systems. The added value of the journal consists of going beyond the publication of an article. The journal will be successful to the extent that published studies, opinions, reviews, etc. take into account the greatest challenge in the field, namely how the efficacy of therapy may be demonstrated. Certainly, articles that convincingly show advances in any therapeutic aspect related to NSDs are welcome. Reports on potential biomarkers whose measurement can be carried out in a living human being (rather than in postmortem tissue) will be critical in overcoming the challenges of demonstrating the efficacy of neuroprotective therapies. Articles in which novel strategies to determine efficacy are pursued, e.g., longitudinal trials in humans and/or animal models, are very welcome. Finally, the journal would like to include innovative ideas on technological developments to discover biomarkers that can be measured in living humans, e.g., using probes and nanotechnology or telemetry to detect in real-time glucose and oxygen levels in the cerebrospinal fluid.

\section{Abbreviations}

AD: Alzheimer's disease

CSF: cerebrospinal fluid

ENT: Exploration of Neuroprotective Therapy

NSD: nervous system disease

PD: Parkinson's disease

\section{Declarations}

\section{Author contributions}

The author contributed solely to the work.

\section{Conflicts of interest}

The author declares no conflicts of interest.

\section{Ethical approval}

Not applicable.

\section{Consent to participate}

Not applicable. 


\section{Consent to publication}

Not applicable.

Availability of data and materials

Not applicable.

\section{Funding}

Supported by grant \# RTI2018-094204-B-I00 from the Spanish Ministry of Science and Innovation; it includes EU FEDER funds. The funder had no role in study design, data collection and analysis, decision to publish, or preparation of the manuscript.

\section{Copyright}

(C) The Author(s) 2021.

\section{References}

1. Kalia LV, Lang AE. Parkinson's disease. Lancet. 2015;386:896-912.

2. Tysnes OB, Storstein A. Epidemiology of Parkinson's disease. J Neural Transm (Vienna). 2017;124:901-5.

3. Elbaz A, Carcaillon L, Kab S, Moisan F. Epidemiology of Parkinson's disease. Rev Neurol (Paris). 2016;172:14-26.

4. Silva MVF, Loures CDMG, Alves LCV, de Souza LC, Borges KBG, Carvalho MDG. Alzheimer's disease: risk factors and potentially protective measures. J Biomed Sci. 2019;26:33.

5. Ye Q Bai F, Zhang Z. Shared genetic risk factors for late-life depression and Alzheimer's disease. J Alzheimer's Dis. 2016;52:1-15.

6. Hersi M, Irvine B, Gupta P, Gomes J, Birkett N, Krewski D. Risk factors associated with the onset and progression of Alzheimer's disease: a systematic review of the evidence. Neurotoxicology. 2017;61:143-87.

7. Cacace R, Sleegers K, Van Broeckhoven C. Molecular genetics of early-onset Alzheimer's disease revisited. Alzheimer's Dement. 2016;12:733-48.

8. Ballard C, Gauthier S, Corbett A, Brayne C, Aarsland D, Jones E. Alzheimer's disease. Lancet. 2011;377:1019-31.

9. Nikolac Perkovic M, Pivac N. Genetic markers of Alzheimer's disease. In: advances in experimental medicine and biology. 2019;1192:27-52.

10. Franco R, Fernández-Suárez D. Alternatively activated microglia and macrophages in the central nervous system. Prog Neurobiol. 2015;131:65-86.

11. Ni R, Mu L, Ametamey S. Positron emission tomography of type 2 cannabinoid receptors for detecting inflammation in the central nervous system. Acta Pharmacol Sin. 2018;40:351-7.

12. Evens N, Bormans GM. Non-invasive imaging of the type 2 cannabinoid receptor, focus on positron emission tomography. Curr Top Med Chem. 2010;10:1527-43.

13. Cicchetti F, Brownell AL, Williams K, Chen YI, Livni E, Isacson O. Neuroinflammation of the nigrostriatal pathway during progressive 6-OHDA dopamine degeneration in rats monitored by immunohistochemistry and PET imaging. Eur J Neurosci. 2002;15:991-8.

14. Gerhard A, Banati RB, Goerres GB, Cagnin A, Myers R, Gunn RN, et al. $\left[{ }^{11} \mathrm{C}\right](R)$-PK11195 PET imaging of microglial activation in multiple system atrophy. Neurology. 2003;61:686-9.

15. Catafau AM, Bullich S. Non-amyloid PET imaging biomarkers for neurodegeneration: focus on tau, alphasynuclein and neuroinflammation. Curr Alzheimer Res. 2016;14:169-77.

16. Kallinen A, Boyd R, Lane S, Bhalla R, Mardon K, Stimson DHR, et al. Synthesis and in vitro evaluation of fluorine-18 benzimidazole sulfones as CB2 PET-radioligands. Org Biomol Chem. 2019;17:5086-98.

17. Edison P, Ahmed I, Fan Z, Hinz R, Gelosa G, Ray Chaudhuri K, et al. Microglia, amyloid, and glucose metabolism in Parkinson's disease with and without dementia. Neuropsychopharmacology. 2013;38:938-49. 
18. Pavese N, Gerhard A, Tai YF, Ho AK, Turkheimer F, Barker RA, et al. Microglial activation correlates with severity in Huntington disease: a clinical and PET study. Neurology. 2006;66:1638-43.

19. Cagnin A, Brooks DJ, Kennedy AM, Gunn RN, Myers R, Turkheimer FE, et al. In vivo measurement of activated microglia in dementia. Lancet. 2001;358:461-7.

20. Janssen B, Vugts DJ, Windhorst AD, Mach RH. PET imaging of microglial activation-beyond targeting TSPO. Molecules. 2018;23:607.

21. Moodley N, Ngxamngxa U, Turzyniecka MJ, Pillay TS. Historical perspectives in clinical pathology: a history of glucose measurement. J Clin Pathol. 2015;68:258-64.

22. Middleton JE, Griffiths WJ. Rapid colorimetric micro-method for estimating glucose in blood and C.S.F. using glucose oxidase. Br Med J. 1957;2:1525-7.

23. Larsen ML, Horder M, Mogensen EF. Effect of long-term monitoring of glycosylated hemoglobin levels in insulin-dependent diabetes mellitus. N Engl J Med. 1990;323:1021-5.

24. Engbaek F, Christensen SE, Jespersen B. Enzyme immunoassay of hemoglobin A1c: analytical characteristics and clinical performance for patients with diabetes mellitus, with and without uremia. Clin Chem. 1989;35:93-7.

25. Wu VY, Steward LA, cohen MP. Purification of glycated hemoglobin free of hemoglobin A1c and its use to produce monoclonal antibodies specific for deoxyfructosyllsine residues in glycohemoglobin. Biochem Biophys Res Commun. 1991;176:207-12.

26. Rose A, Tongate C, Valdes R. A hemoglobin A1c immunoassay method not affected by carbamylated hemoglobin. Ann Clin Lab Sci. 1995;25:13-9.

27. Mazze R, Akkerman B, Mettner J. An overview of continuous glucose monitoring and the ambulatory glucose profile. Minn Med. Minn Med; 2011;94:40-4.

28. Spanakis EK, Levitt DL, Siddiqui T, Singh LG, Pinault L, Sorkin J, et al. The effect of continuous glucose monitoring in preventing inpatient hypoglycemia in general wards: the glucose telemetry system. J Diabetes Sci Technol. 2018;12:20-5.

29. Wang B, Sun G, Qiao W, Liu Y, Qiao J, Ye W, et al. Long-term blood glucose monitoring with implanted telemetry device in conscious and stress-free cynomolgus monkeys. J Endocrinol Invest. 2017;40:967-77.

30. Lucisano JY, Routh TL, Lin JT, Gough DA. Glucose monitoring in individuals with diabetes using a long-term implanted sensor/telemetry system and model. IEEE Trans Biomed Eng. 2017;64:1982-93.

31. Eskelinen MH, Kivipelto M. Caffeine as a protective factor in dementia and Alzheimer's disease. J Alzheimer's Dis. 2010;20 Suppl 1:S167-74.

32. Sindi S, Kåreholt I, Eskelinen M, Hooshmand B, Lehtisalo J, Soininen H, et al. Healthy dietary changes in midlife are associated with reduced dementia risk later in life. Nutrients. 2018;10:1649.

33. Cunha RA. Cafeine, adenosina receptors, memory and Alzheimer's disease. Med Clin (Barc). 2008;131:790-5.

34. Eskelinen MH, Ngandu T, Tuomilehto J, Soininen H, Kivipelto M. Midlife coffee and tea drinking and the risk of late-life dementia: a population-based CAIDE study. J Alzheimer's Dis. 2009;16:85-91.

35. Eskelinen MH, Ngandu T, Tuomilehto J, Soininen H, Kivipelto M. Midlife healthy-diet index and late-life dementia and Alzheimer's disease. Dement Geriatr Cogn Dis Extra. 2011;1:103-12.

36. Gauthier S, Albert M, Fox N, Goedert M, Kivipelto M, Mestre-Ferrandiz J, et al. Why has therapy development for dementia failed in the last two decades? Alzheimer's Dement. 2016;12:60-4.

37. Ngandu T, Lehtisalo J, Solomon A, Levälahti E, Ahtiluoto S, Antikainen R, et al. A 2 year multidomain intervention of diet, exercise, cognitive training, and vascular risk monitoring vs. control to prevent cognitive decline in at-risk elderly people (FINGER): a randomised controlled trial. Lancet. 2015;385:2255-63.

38. Franco R. Café y salud mental coffee and mental health. Aten Primaria. 2009;41:578-81. 
39. Onatibia-Astibia A, Franco R, Martínez-Pinilla E. Health benefits of methylxanthines in neurodegenerative diseases. Mol Nutr Food Res. 2017;61:1600670.

40. Morano A, Jiménez-Jiménez FJ, Molina JA, Antolín MA. Risk-factors for Parkinson’s disease: case-control study in the province of Cáceres, Spain. Acta Neurol Scand. 1994;89:164-70.

41. Maia L, de Mendonça A. Does caffeine intake protect from Alzheimer's disease? Eur J Neurol. 2002;9:377-82.

42. Franco R, Martínez-Pinilla E, Navarro G. Why have transgenic rodent models failed to successfully mimic Alzheimer's disease. How can we develop effective drugs without them? Expert Opin Drug Discov. 2019;14:327-30.

43. Hopkins Tanne J. Approved drugs are to be studied for use in Alzheimer's disease. BMJ. 2016;354:15063.

44. Blusztajn JK, Slack BE, Mellott TJ. Neuroprotective actions of dietary choline. Nutrients. 2017;9:815.

45. Lopresti AL. Salvia (sage): a review of its potential cognitive-enhancing and protective effects. Drugs $\mathrm{R}$ D. 2017;17:53-64.

46. Wu CY, Hu HY, Chow LH, Chou YJ, Huang N, Wang PN, et al. The effects of anti-dementia and nootropic treatments on the mortality of patients with dementia: a population-based cohort study in Taiwan. PLoS One. 2015;10:e0130993.

47. Ziganshina LE, Abakumova T, Vernay L. Cerebrolysin for acute ischaemic stroke. Cochrane Database Syst Rev. 2017;4:CD007026.

48. Canhada S, Castro K, Perry IS, Luft VC. Omega-3 fatty acids' supplementation in Alzheimer's disease: a systematic review. Nutr Neurosci. 2018;8:529-38.

49. Wilms W, Woźniak-Karczewska M, Corvini PFX, Chrzanowski L. Nootropic drugs: methylphenidate, modafinil and piracetam-population use trends, occurrence in the environment, ecotoxicity and removal methods-a review. Chemosphere. 2019;233:771-85.

50. Perng $\mathrm{CH}$, Chang YC, Tzang RF. The treatment of cognitive dysfunction in dementia: a multiple treatments meta-analysis. Psychopharmacology (Berl). 2018;235:1571-80. 